\title{
CAPÍTULO 12: ANÁLISE DO PERFIL DO CONSUMIDOR SOBRE A REFRIGERAÇÃO DOS OVOS DE GALINHA
}

\section{CAPÍTULO 12: ANÁLISIS DEL PERFIL DEL CONSUMIDOR SOBRE EL ENFRIAMIENTO DE HUEVOS DE POLLO}

\section{CHAPTER 12: CONSUMER PROFILE ANALYSIS ON CHILLING OF CHICKEN EGGS}

\author{
Emily Miskiw ${ }^{1}$; Mauro de Lima ${ }^{2}$; Grazieli Suszek ${ }^{3}$; Izabeli de Sousa Rocha ${ }^{4}$, Maria Antônia Neves ${ }^{5}$
}

DOI: https://doi.org/10.31692/978-65-88970-18-8.171-184

\begin{abstract}
RESUMO
O ovo é um alimento perecível, por isso a perda da sua qualidade interna ocorre logo após a postura. A forma que ele é armazenado entre o intervalo da postura e a aquisição do ovo pelo consumidor, influencia na sua qualidade final. Para a redução de deterioração dessa qualidade a maneira mais simples é a refrigeração, onde ela não mata os microrganismos, mas sim dificulta que seu ciclo de produção continue. Nessa perspectiva, objetivou-se com esse trabalho analisar o perfil do consumidor com relação a refrigeração dos ovos de galinha. Para a obtenção dos dados optou-se pelo uso de questionário via internet e presencial, no total tivemos 351 respostas dos diversos produtores e consumidores entrevistados. Dos entrevistados $86 \%$ refrigera o ovo, $12 \%$ mantém o ovo em temperatura ambiente e apenas $2 \%$ armazena o ovo dos dois jeitos, dessas pessoas $87 \%$ sabem a importância da refrigeração dos alimentos e os $13 \%$ restantes não sabem sobre a importância da refrigeração para a conservação dos ovos. Os dados mostram que uma parte considerável das pessoas não sabem que a refrigeração é de extrema importância para manter a qualidade do ovo além de aumentar o tempo de armazenamento, por isso ficou claro que é importante fazer a divulgação dessas informações para os produtores e consumidores através de campanhas de cunho educativo sobre a importância da refrigeração para que eles tenham conhecimento sobre os benefícios da refrigeração além disso pode haver mudanças na forma que eles armazenam os ovos.
\end{abstract}

Palavras-chave: Armazenamento, qualidade do ovo, refrigeração, questionário.

\section{RESUMEN}

El huevo es un alimento perecedero, por lo que la pérdida de su calidad interna se produce poco después de la puesta. El modo de almacenamiento entre el intervalo de puesta y la compra del huevo por el consumidor influye en su calidad final. Para reducir el deterioro de esta calidad, la forma más sencilla es la refrigeración, que no mata a los microorganismos, pero impide que su ciclo de producción continúe. Desde esta perspectiva, este estudio tenía como objetivo analizar el perfil del consumidor respecto a la refrigeración de los huevos de gallina. Para obtener los datos se optó por el uso de cuestionarios vía internet y presenciales, en total se obtuvieron 351 respuestas de varios productores y consumidores entrevistados. De los entrevistados, el $86 \%$ refrigera los huevos, el $12 \%$ los mantiene a temperatura ambiente y sólo el $2 \%$ los almacena de ambas formas. De estas personas, el $87 \%$ conoce la importancia de la refrigeración de los alimentos y el $13 \%$ restante no sabe de la importancia de la refrigeración para la conservación de los huevos. Los datos muestran que una parte considerable de las personas no saben que la refrigeración es sumamente importante para mantener la calidad del huevo además de aumentar el tiempo de almacenamiento, por lo que quedó claro que es importante hacer la difusión de esta información a los productores y consumidores a través de campañas educativas sobre la importancia de

\footnotetext{
${ }^{1}$ Graduanda do curso Técnico Integrado em Agropecuária, Instituto Federal de Mato Grosso do Sul, emily.miskiw@estudante.ifms.edu.br

${ }^{2}$ Graduado em Engenharia Agrícola, Universidade Estadual do Oeste do Paraná, mauro.lima@ifms.edu.br

${ }^{3}$ Doutora em Engenharia Agrícola, Universidade Estadual do Oeste do Paraná, grazieli.suszek@ifms.edu.br

${ }^{4}$ Graduanda do curso Técnico Integrado em Agropecuária, Instituto Federal de Mato Grosso do Sul, izabeli.rocha@estudante.ifms.edu.br

${ }^{5}$ Graduanda do curso de Agronomia, Instituto Federal de Mato Grosso do Sul, maria.neves@ estudante.ifms.edu.br
} 
la refrigeración para que tengan conocimiento sobre los beneficios de la refrigeración y pueda haber cambios en la forma de almacenar los huevos.

Palabras clave: Almacenamiento, calidad del huevo, refrigeración, cuestionario.

\begin{abstract}
The egg is a perishable food, so the loss of its internal quality occurs soon after laying. The way it is stored between the laying interval and the egg purchase by the consumer influences its final quality. To reduce the deterioration of this quality the simplest way is refrigeration, where it does not kill the microorganisms, but hinders its production cycle to continue. In this perspective, the aim of this study was to analyze the consumer profile regarding the refrigeration of chicken eggs. To obtain the data we chose to use a questionnaire via the Internet and in person. In total we had 351 answers from several producers and consumers interviewed. From the interviewees, $86 \%$ refrigerate their eggs, $12 \%$ keep them at room temperature and only $2 \%$ store them both ways. From these people, $87 \%$ know the importance of food refrigeration and the remaining $13 \%$ do not know about the importance of refrigeration for the preservation of eggs. The data show that a considerable part of the people don't know that refrigeration is extremely important to maintain the quality of the egg besides increasing the storage time, so it was clear that it is important to spread this information to producers and consumers through educational campaigns about the importance of refrigeration so that they have knowledge about the benefits of refrigeration besides that there may be changes in the way they store eggs.
\end{abstract}

Keywords: Storage, egg quality, refrigeration, questionnaire.

\title{
INTRODUÇÃO
}

O Brasil deve produzir 49 bilhões de unidades de ovos neste ano de 2019. O montante representa um crescimento de $10 \%$ em relação às 44,4 bilhões produzidas em 2018, conforme os dados da Associação Brasileira de Proteína Animal (ABPA), (MENDES, 2020).

O ovo de galinha é um dos alimentos naturais mais completos, que oferece às pessoas um balanço quase completo de nutrientes essenciais, como proteínas de excelente valor biológico, vitaminas, minerais e ácidos graxos (BARBOSA et al, 2009). Sendo um alimento perecível, começa a perder sua qualidade interna imediatamente após a postura (FERNANDES et al., 2015). Essa redução da qualidade está ligada a perda de água e de dióxido de carbono, isso acontece também durante o período de estocagem e é proporcional ao aumento da temperatura (JUCÁ et al, 2011). Por terem seus constituintes naturalmente protegidos pela casca, a qualidade do albúmen se torna notória somente quando o comprador for utilizá-lo (SMITH; NGUYEN, 1984).

Lana e Viana (2017), destacam que é inevitável a perda da qualidade do ovo, pois ela é contínua e se inicia logo após a postura, ela pode ser agravada por fatores como temperatura, umidade relativa e estado nutricional da poedeira. Para preservar o valor nutricional do ovo é fundamental que ele seja conservado de maneira correta durante todo o período de comercialização. Vale destacar que a validade máxima de um ovo, em temperatura ambiente, 


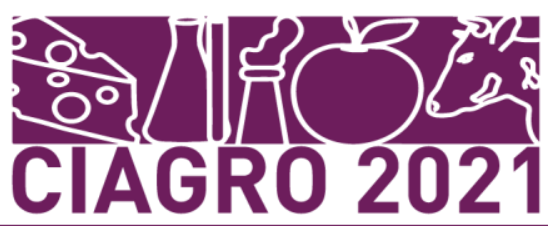

sem deteriorar a sua qualidade interna, varia de quatro a quinze dias após a data de postura (OLIVEIRA, 2000).

Para melhorar esse tempo de validade temos a refrigeração, Lino (2014), diz que podemos definir refrigeração como o abaixamento da temperatura de um produto visando manter a qualidade pela diminuição das velocidades das reações de deterioração que possam ocorrer nos alimentos.

A refrigeração dos alimentos, não elimina os microrganismos que fazem mal a saúde ou que auxiliam para a degradação, mas dificulta que seu ciclo de reprodução continue prolongando a deterioração deste quando atacados, que impede de certa forma, que altere a qualidade do alimento, evitando a perda dos mesmos, com isso a qualidade inicial do alimento é preservada e prolongada por um período de tempo um pouco maior que sua vida útil (LINO, 2014). De acordo com Nobrega (2019), os ovos após 21 dias em refrigeramento mantém suas estruturas internas conservadas comparada aos ovos mantidos em temperatura ambiente.

Segundo Lana (2017), a refrigeração dos ovos não é obrigatória pela legislação brasileira, por isso os ovos são conservados em temperaturas ambientes $\left(20^{\circ} \mathrm{C}\right.$ a $30^{\circ} \mathrm{C}$ segundo Fernandes (2015)) do momento da postura até a distribuição final, que possivelmente só serão acondicionados sob refrigeração por alguns consumidores.

Tendo como o objetivo dessa pesquisa a análise do perfil do consumidor com relação a refrigeração dos ovos de galinha. Com as informações adquiridas através da pesquisa quantitativa, realizamos análises de maneira que conseguimos demonstrar como o armazenamento dos ovos está sendo feito. Para obtenção dos dados, aplicamos um questionário, previamente produzido, no qual, concederá informações para realizarmos as análises necessárias, a fim de definirmos como os entrevistados fazem o acondicionamento dos ovos.

A pesquisa desenvolvida foi para proporcionar informações sobre como os entrevistados acondicionam os ovos, pois a forma que se é armazenado influência de forma direta no tempo de prateleira, e o não armazenamento adequado pode acarretar em uma degradação mais rápida do ovo. Com a realização dessa pesquisa, e o resultado das análises feitas, teremos parâmetros suficientes para novas etapas da difusão do tema.

\section{FUNDAMENTAÇÃO TEÓRICA}

Segundo Lana (2017), o ovo, que é um produto perecível, começa a perder a qualidade interna logo após a postura, devido a temperatura, umidade relativa e estado nutricional da poedeira. A redução da qualidade dos ovos está associada também à perda de água e de dióxido 
de carbono, durante o período de armazenamento, e também devido ao aumento da temperatura do ambiente (PISSINATI et al, 2014).

Conforme os resultados obtidos por Figueiredo (2011), os ovos mantidos sob refrigeração, apresentam melhor qualidade interna por um maior período de tempo que aqueles mantidos em temperatura ambiente durante o armazenamento. A refrigeração possibilita manter a qualidade interna do ovo apropriada para o consumo por até 25 dias após a postura (LOPES et al., 2012). De acordo com Henriques (2018), cabe ao consumidor fazer o armazenamento dos ovos de forma correta, para que a qualidade dos mesmos não seja afetada e o tempo de prateleira seja maior.

\section{METODOLOGIA}

A pesquisa consistiu na realização de uma formação teórica sobre o assunto escolhido, efetuou-se uma pesquisa bibliográfica e análise preliminar sobre o assunto pesquisado. Foi aplicado dois questionários para saber o perfil dos produtores e consumidores de ovos. A coleta de dados foi realizada de duas formas, um questionário feito pela internet e outro de maneira presencial com os entrevistados.

O questionário prestou-se a investigar o conhecimento dos entrevistados sobre a compreensão que eles têm da conservação do ovo, através das informações que conseguimos nós geramos os dados de como os entrevistados armazenam os ovos entre outras informações. O questionário online foi uma forma de desenvolver a pesquisa durante a pandemia, pois tivemos que fazer uma adequação na rotina de execução das atividades, devido ao distanciamento social imposto pela covid-19. O questionário possuía treze perguntas e foi realizado pela plataforma Google Formulários (Figura 2). 


\section{Figura 2. Como foi disponibilizado o questionário.}

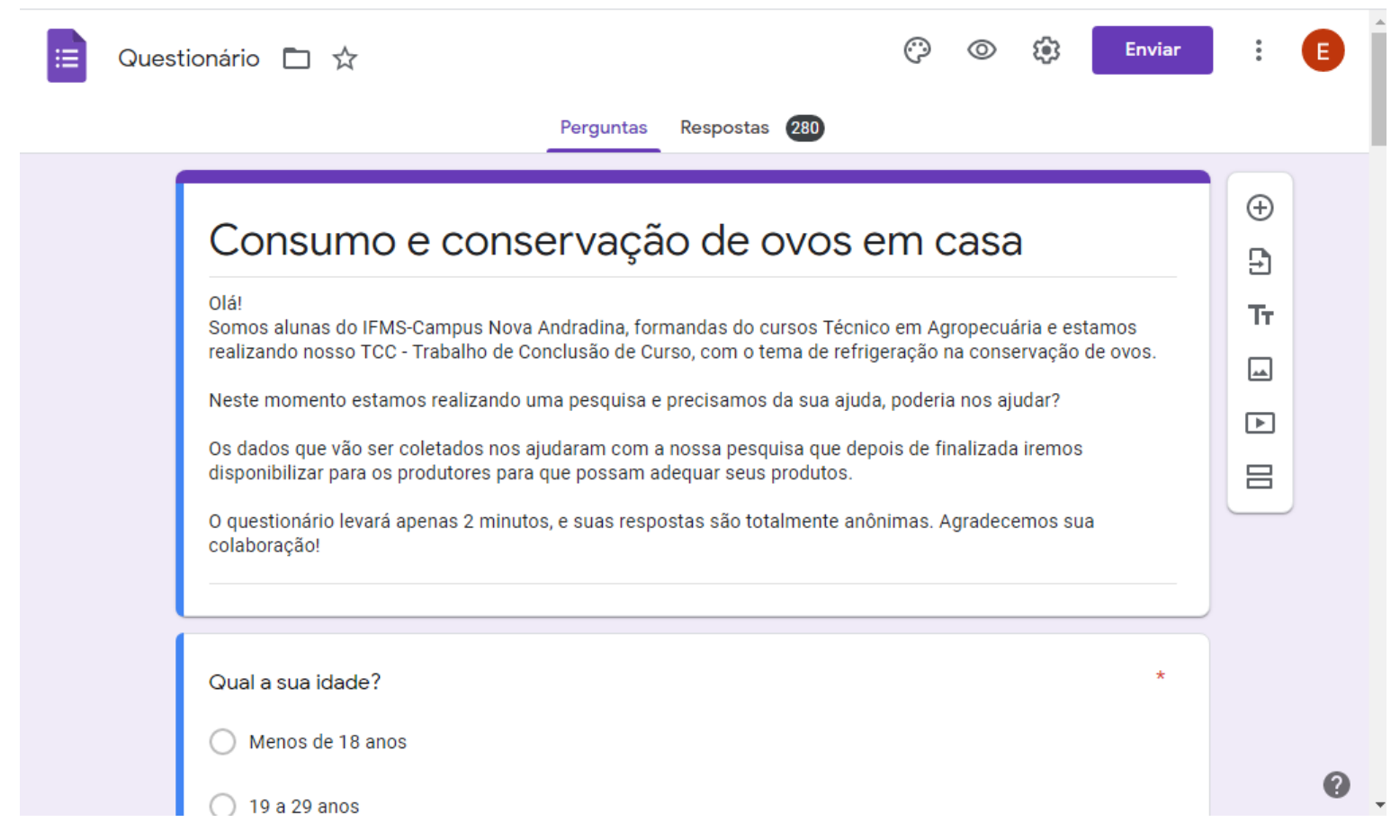

Fonte: Própria (2020)

Utilizamos o aplicativo de conversa whatsapp para disponibilizar o link do questionário online, no qual os produtores e consumidores puderam respondê-lo, com isso obteve um total de 280 respostas. Diante disso montamos um segundo questionário, ele apresentava dez perguntas sobre o tema, elas foram feitas para as pessoas que frequentam os mercados da região de Nova Andradina-MS, foram realizadas 71 entrevistas.

Após as entrevistas, foi criado um questionário na plataforma Google Formulários onde foram passadas todas as 71 respostas do questionário presencial, para facilitar as análises.

Com os dados dos dois questionários e os gráficos gerados para cada uma das perguntas na plataforma Google Formulários, ocorreu uma análise superficial dos resultados, ou seja, foi observado ambos os questionários e estudado qual seria as possíveis discussões.

Após isso, definimos 10 questões que se repetiam nos dois questionários e agrupamos esses resultados no Excel, onde foram gerados os gráficos da junção dos dois questionários e então feito as discussões sobre o mesmo.

\section{RESULTADOS E DISCUSSÃO}

Foram realizadas 351 (Figura 3) entrevistas da pesquisa, com os seguintes resultados, onde $84 \%$ dos entrevistados tinham mais de 19 anos, que houve também uma grande variação nas idades dos entrevistados mostrando que o ovo é consumido por todas as idades. 
Figura 3. Idade que as pessoas tinham quando foi feita a pesquisa.

\section{Qual a sua idade?}

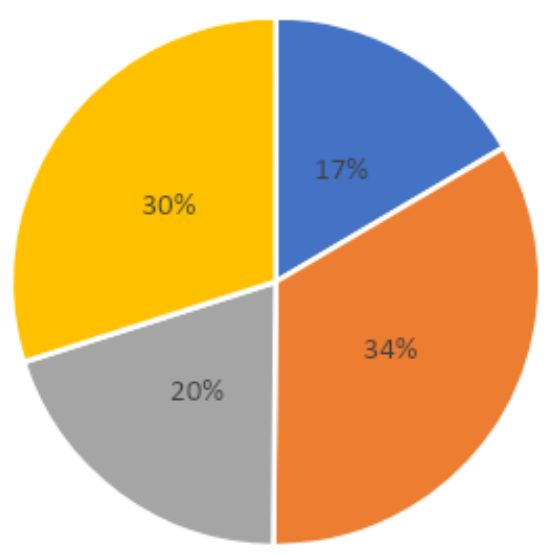

Menos de 18 anos

- 19 a 29 anos

- 30 aos 40 anos

Acima de 40 anos

Fonte: Própria (2020)

Conforme a Figura 4 temos, 66\% dos entrevistados tinham no mínimo o ensino médio, havendo dentro desses pós-graduados e com ensino superior já os outros $44 \%$ tinham o ensino fundamental completo ou incompleto, vendo também que o ovo é consumido independente da escolaridade.

Figura 4. Escolaridade das pessoas entrevistadas.

\section{Qual a sua escolaridade?}

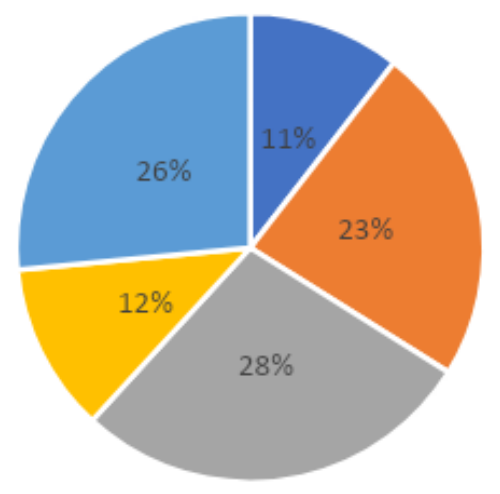

Ensino fundamental

incompleto

Ensino fundamental

Ensino médio

Ensino superior

- Pós graduação

Fonte: Própria (2020)

Dessas entrevistas (Figura 5), 86\% refrigera o ovo, 12\% dos entrevistados mantém o ovo em temperatura ambiente e apenas $2 \%$ armazena o ovo dos dois jeitos. Conforme os dados 
da pesquisa, podemos observar que ainda existe um público de $14 \%$ entre os entrevistados que não armazenam os ovos em um ambiente refrigerado. A refrigeração não melhora a qualidade do produto, mas diminui a taxa respiratória em tecidos vivos, reduzindo a velocidade de deterioração e evita o crescimento da maioria dos patógenos (ESTELLES, 2003).

Figura 5. Como as pessoas armazenam os ovos.

\section{Como você armazena os ovos?}

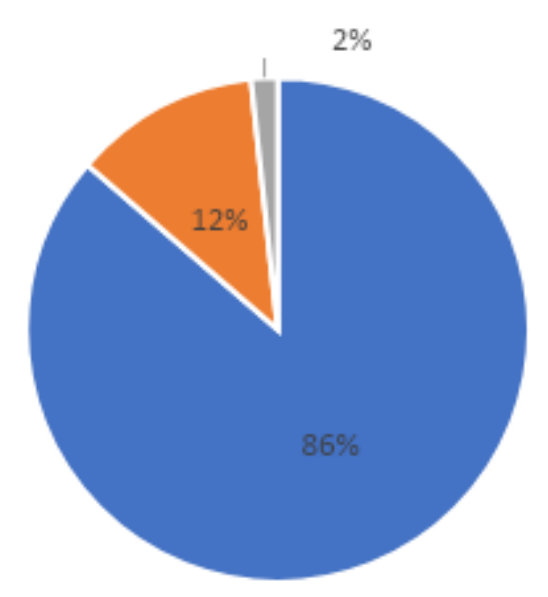

Em resfriamento (na geladeira) Em temperatura ambiente Em temperatura ambiente, Em resfriamento (na geladeira)

Fonte: Própria (2020)

De acordo com Silva (2001), conforme citado por Estelles, "a preservação dos alimentos se faz necessária na tentativa de se resolver o problema do desperdício e melhorar o aproveitamento integral dos alimentos, para posterior consumo".

$\mathrm{Na}$ Figura 6, podemos observar que $42 \%$ dos entrevistados consome mais de 25 ovos por mês, onde segundo Oliveira (2000) os ovos armazenados em temperatura ambiente podem se deteriorar em quatro a quinze dias, mas quando armazenados em temperatura refrigerada podem ser armazenados por mais tempo sem perder a qualidade (NOBREGA, 2019). Os outros $58 \%$ restantes, $45 \%$ consomem entre 7 e 24 ovos por mês e apenas $13 \%$ consomem até 6 ovos por mês. 


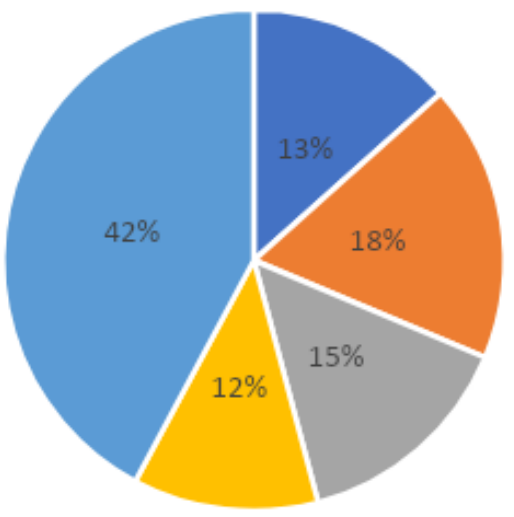

Até 6 ovos

De 7 a 12 ovos

De 13 a 18 ovos

De 19 a 24 ovos

Acima de 25 ovos

Fonte: Própria (2020)

Esses mesmos entrevistados $79 \%$ consomem os ovos de 15 dias a 1 mês, sabendo que segundo Oliveira (2000) a validade máxima do ovo é de 15 dias após postura, lembrando que ainda há um entre a postura e a compra que geralmente não é no mesmo dia, apenas $21 \%$ dos entrevistados consomem o ovo com uma certa segurança que em 7 dias após a compra.

Figura 7. Tempo que as pessoas levam para consumir os ovos que elas compram.

\section{Em quanto tempo costuma consumir os ovos?}

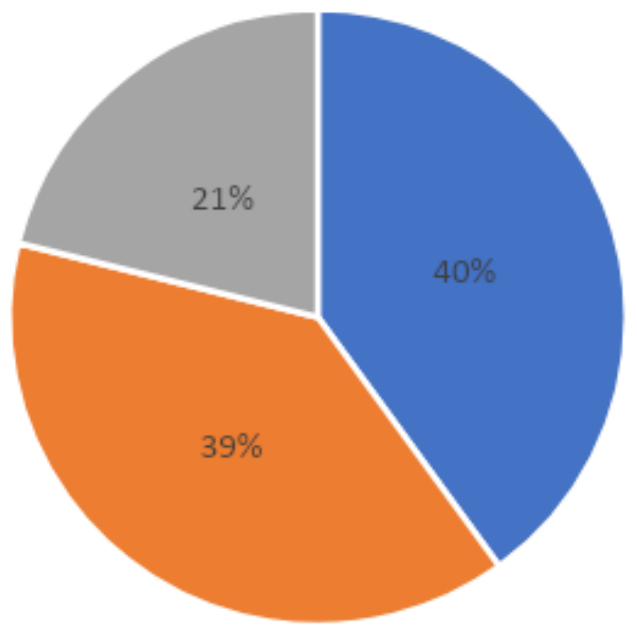


$\mathrm{Na}$ hora de comprar os ovos, os entrevistados observam algumas características que dizem ser características de ovos de qualidade, a Figura 8 mostra que 45\% das pessoas analisam o tamanho do ovo, $25 \%$ olha a aparência da casca, $13 \%$ a cor, $10 \%$ a validade do produto, $1 \%$ observa outras coisas e $1 \%$ não olha nada. Apenas $10 \%$ dos entrevistados olha a validade do produto. É importante olhar a validade do produto, pois é através dela que nós vamos saber até quando que o ovo pode ser consumido com segurança, porque se passar do prazo de validade o ovo pode causar alguma intoxicação e o alimento também pode estar estragado depois da data determinada.

Figura 8. Características observadas antes de comprar os ovos.

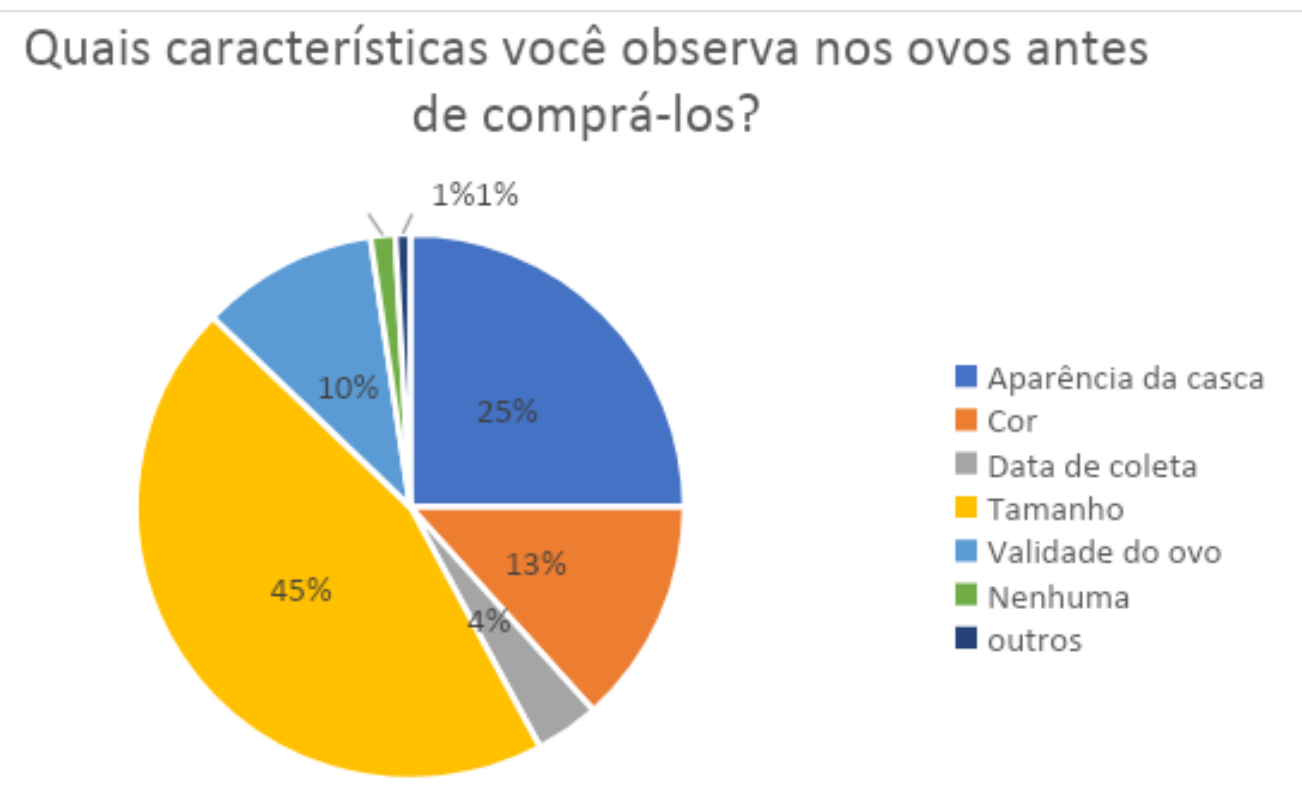

Fonte: Própria (2020)

Na figura 9, observamos que $91 \%$ dos entrevistados sabem que o ovo é um alimento perecível e apenas $9 \%$ não sabem. 


\section{Você sabe que o ovo é um produto perecível?}

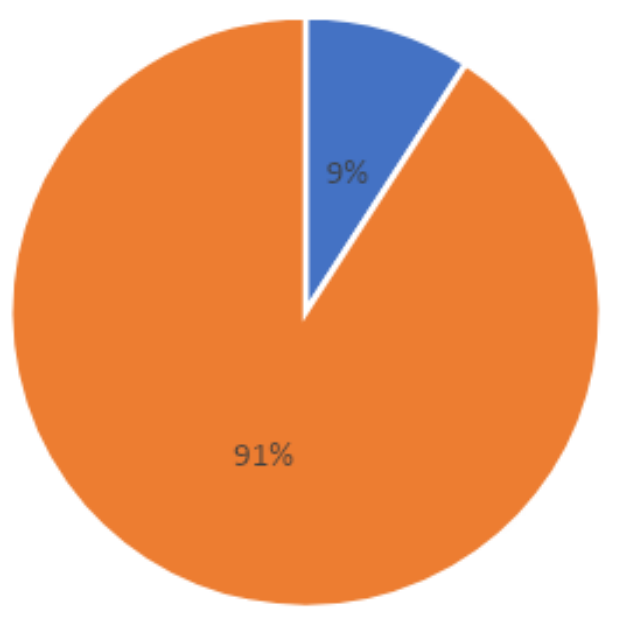

Fonte: Própria (2020)

Já na Figura 10, 90\% dos entrevistados deixam o ovo refrigerado, enquanto $10 \%$ o deixam em temperatura ambiente.

Figura 10. Como é refrigerado os ovos nas casas dos entrevistados.

\section{Você costuma deixar os ovos refrigerados em casa?}

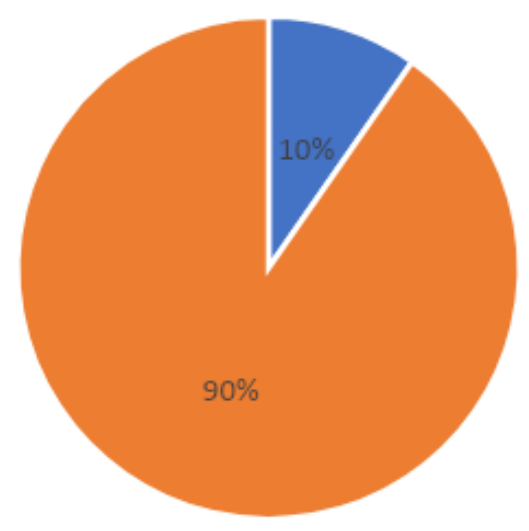

Contudo observamos que $91 \%$ sabem que o ovo é um alimento perecível como apresenta na figura 9 e mesmo assim quando comparamos a diferença entre os entrevistados 
que sabem que o ovo é um alimento perecível e os que armazenam em refrigeração, vemos que

$1 \%$ destes ainda o armazenam em temperatura ambiente tal como mostra na figura 10.

Nas Figuras 11 e 12 os resultados foram semelhantes, sendo que a Figura 11 apresenta a porcentagem dos entrevistados que sabem a importância da refrigeração para conservação dos alimentos, e na Figura 12 a preservação do ovo em um ambiente refrigerado. Finalizando a análise dos dados, os dois casos apresentados, $87 \%$ dos entrevistados sabem a importância da conservação dos alimentos e que o alimento refrigerado é preservado por mais tempo, incluindo o ovo. Já os $13 \%$ restantes não sabem sobre a importância da conservação dos alimentos e nem sobre a importância da refrigeração dos ovos.

Figura 11. Importância da refrigeração para conservação do alimento.

Você sabe da importância da refrigeração para a conservação de alimentos?

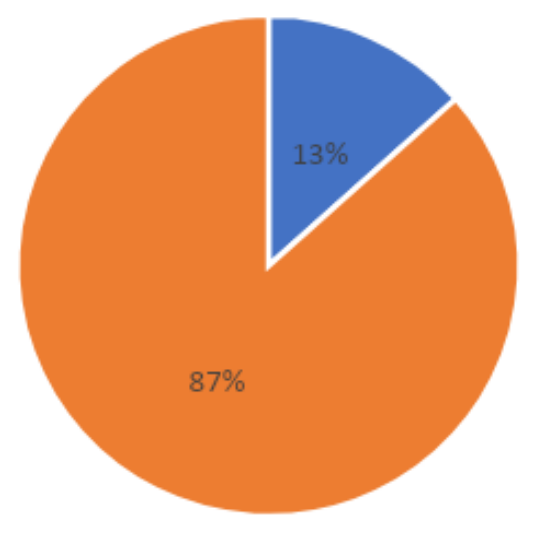

Fonte: Própria (2020)

Figura 12. Refrigeração e conservação do ovo. 


\section{Você sabe que o ovo refrigerado é preservado por \\ mais tempo?}

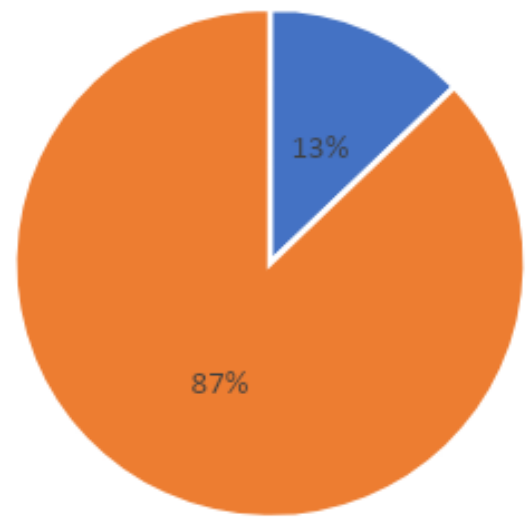

Fonte: Própria (2020)

\section{CONCLUSÕES}

Concluímos que com a análise dos resultados dos questionários, ficou claro que ainda há necessidade da implementação de campanhas de cunho educativo sobre a importância da refrigeração e a importância de observar a validade dos ovos de galinha, já que $12 \%$ dos entrevistados não armazena os ovos sob refrigeração e apenas $10 \%$ dos entrevistados olham a validade dos ovos. Sendo então, importante a divulgação para que os consumidores e produtores aprendam sobre os benefícios da refrigeração, pois aumenta o tempo de armazenagem dos ovos e com isso pode haver uma mudança na forma que eles armazenam os ovos.

\section{REFERÊNCIAS}

BARBOSA, N. A. A. et al. Qualidade de ovos comerciais provenientes de poedeiras comerciais armazenados sob diferentes tempos e condições de ambientes. Ars Veterinaria, v. 24, n. 2, p. 127-133, 2009. Disponível em: <http://arsveterinaria.org.br/index.php/ars/article/view/182/150>. Acesso em: 22 de Out. de 2019.B

ESTELLES, R. S. Importância do controle da temperatura e do tratamento térmico na preservação dos nutrientes e da qualidade de alimentos. Brasília-DF, Jan. 2003. Disponível em: <https://bdm.unb.br/bitstream/10483/246/1/2003_RenataSoaresEstelles.pdf >. Acesso em: 07 de Dez. de 2020.

FERNANDES, D. P. B. et al. Qualidade interna de diferentes tipos de ovos comercializados durante o inverno e o verão. Arquivo Brasileiro de Medicina Veterinária e Zootecnia, v. 67, 
n. 4, p. 1159-1165, 2015.Disponível em: <https://www.scielo.br/scielo.php?pid=S0102$09352015000401159 \&$ script $=$ sci_arttext\&tlng=pt $>$. Acesso em: 12 de Maio de 2020.

FIGUEIREDO, T. C. et al. Qualidade de ovos comerciais submetidos a diferentes condições de armazenamento. Arq. Bras. Med. Vet. Zootec. 2011. Disponível em: < https://www.scielo.br/pdf/abmvz/v63n3/v63n3a24.pdf > Acesso em: 25 de Set. de 2020.

HENRIQUES. J. K. S, et al. Qualidade de ovos comerciais submetidos a diferentes condições de armazenamento. Revista Brasileira de Higiene e Sanidade Animal, v.12, n.2 p. 179 -189 abr - jun. 2018. Acesso em: 2021.

JUCÁ, T. S. et al. Efeito do tempo e condições de armazenamento sobre a qualidade interna de ovos de poedeiras isa brown produzidos em diferentes sistemas de criação e ambiência. Enciclopédia Biosfera, Centro Científico Conhecer, v. 7, n. 13, p. 446, 2011. Acesso em: 13 de Mar. 2020.

LANA, S. R. V. et al. Qualidade de ovos de poedeiras comerciais armazenados em diferentes temperaturas e períodos de estocagem. Revista Brasileira de Saúde e Produção Animal, v. 18, n. 1, p. 140-151, 2017. Disponível em: <https://www.scielo.br/pdf/rbspa/v18n1/15199940-rbspa-18-01-0140.pdf>. Acesso em: 24 de Set. de 2020.

LOPES. L. L. R. et al. Influência do tempo e das condições de armazenamento na qualidade de ovos comerciais. Revista científica eletrônica de medicina veterinária - ISSN: 1679-7353 Ano IX - Número 18 - Jan. 2012.

LINO, G. C. L; LINO, T. H. L. Congelamento e refrigeração. Disponível em: $<$ http://paginapessoal.utfpr.edu.br/lopesvieira/operacoes-unitarias/trabalhos/turma-20132/refrigeracao-e-congelamento/refrigeracao\%20e\%20congelamento.pdf/at_download/file>. Acesso em: 09 de Dez. 2020.

MENDES. C. Consumo e produção de ovos crescem em 2019. Anuário' 2020 da Avicultura Industrial. 06 de Jan. 2020. Disponível em: $<$ https://www.aviculturaindustrial.com.br/imprensa/consumo-e-producao-de-ovos-crescemem-2019/20200106-135530-h626>. Acesso em: 09 de Dez. 2020.

MENEZES et al. Egg quality of laying hens in different conditions of storage, ages and housing densities. Revista Brasileira de Zootecnia, 2012. Disponível em: <https://www.scielo.br/pdf/rbz/v41n9/v41n9a14.pdf> Acesso em: 09 de Dez. de 2020.

NOBREGA. A. M. Qualidade de ovos de galinha submetidos a diferentes condições de armazenamento e tempo de estocagem utilizando imagem térmica. 2019. Acesso em: 05 de Dez. 2020.

OLIVEIRA, B. L. Processamento e industrialização de ovos. In: SIMPÓSIO GOIANO DE AVICUltURA, 4., 2000, Goiânia, GO. Anais. Simpósio Goiano De Avicultura. Goiânia, GO: Associação Goiana de Avicultura, p.177-186. 2000.

PISSINATI, A. et al. Qualidade interna de ovos submetidos a diferentes tipos de revestimento e armazenados por 35 dias a $25^{\circ} \mathrm{C}$. Semina: Ciências Agrárias, Londrina, v. 35, n. 1, p. 531-540, jan./fev. 2014. 
Quarterly, v.44, p.94-96, 1984.

VIANA, B. C. et al. Qualidade de ovos produzidos e submetidos à diferentes condições de armazenamento na Amazônia Ocidental, Acre - Brasil. Arq. Ciênc. Vet. Zool. UNIPAR, Umuarama, v. 20, n. 4, p. 201-206, 2017. Disponível em: <https://www.revistas.unipar.br/index.php/veterinaria/article/download/6107/3606>. Acesso em: 24 de Set. de 2020. 